\title{
Contact eczema of hands caused by contact with potato protein
}

\author{
Aleksander Obtułowicz', Magdalena Pirowska', Anna Wojas-Pelc ${ }^{1}$ \\ ${ }^{1}$ Department of Dermatology, Jagiellonian University Medical College, Cracow, Poland
}

Obtułowicz A, Pirowska M, Wojas-Pelc A. Contact eczema of hands caused by contact with potato protein. Ann Agric Environ Med. 2016; 23(2): 377-378. doi: 10.5604/12321966.1203909

\begin{abstract}
Introduction. Protein contact dermatitis (PCD) is an IgE-dependent allergic reaction which, despite enormous progress in knowledge, remains a 'non-diagnosed' nosologic unit in contemporary medicine. Skin lesion, with a chronic and recurring course, are analogous with the clinical picture in allergic contact dermatitis (ACD) and irritant contact dermatitis (ICD); skin patch tests, however, are usually negative. This makes the diagnostics difficult, prevents a correct diagnosis and treatment based on the avoidance of allergen.

Case description. A 48-year-old woman presented with erythemato-squamous skin lesions, accompanied by a strong itching, occurring on hands for about 6 months. The patient attributed the occurrence of skin lesions to household chores, above all - cooking and contact with food. The contact allergy was not confirmed. Positive results of the prick-by-prick test were observed for potato. Based on the above results, contact eczema induced by potato protein was diagnosed. Allergen elimination and use of emolients were prescribed. A complete remission of skin lesions was obtained.

Discussion. PCD is rarely diagnosed, which is why there is no substantial epidemiologic data. It is estimated that about $50 \%$ of cases are related to atopy. This occurs more often in patients with a damaged dermal-epidermal barrier. Most often, the same products eaten by subjects do not produce any effects. A correct assessment of the substance provoking the occurrence of skin lesions is very important, as most often the products concerned are those commonly used in the household. A detailed PCD diagnostics is very important for obtaining the optimal treatment results.
\end{abstract}

\section{Key words}

protein contact dermatitis, potato, prick-by-prick

\section{INTRODUCTION}

Protein contact dermatitis (PCD) is an IgE-dependent allergic reaction which, despite enormous progress in knowledge, remains a "'non-diagnosed' nosologic unit in contemporary medicine. Skin lesion, with a chronic and recurring course, are analogous with the clinical picture in allergic contact dermatitis (ACD) and irritant contact dermatitis (ICD); skin patch tests, however, are usually negative [1]. This makes the diagnostics difficult, prevents a correct diagnosis and treatment based on the avoidance of allergen. A correct assessment of the substance provoking the occurrence of skin lesions is very important, as most often the products concerned are products commonly used in the household: potato, carrot, kiwi, cucumber, lettuce and parsley [2].

\section{CASE STUDY}

A 48-year-old woman presented at the Dermalvenereological Outpatient Clinic of the University Medical College in Krakow, Poland, with erythemato-squamous skin lesions, accompanied by strong itching, occurring on hands for about 6 months. The patient attributed the occurrence of skin lesions to household chores, above all - cooking and contact with food. The local condition at admission corresponded to the picture of lesions from the eczema spectrum: the attention was drawn especially to skin dryness; in some

Address for correspondence: Magdalena Pirowska, Department of Dermatology, Jagiellonian University Medical College, Gołębia 24, 31-007 Cracow, Poland E-mail: pirowska@gmail.com

Received: 5 September 2014; accepted: 02 June 2015 places on the back of hands and between fingers there were erythematous lesions with superficial exfoliation of the epidermis; single, deep fissures, reaching the dermis, were observed on finger tips [Fig. 1]. In the allergologic history, the patient reported an allergy to plant pollens, confirmed by prick tests. In order to enhance the diagnostics, classical epidermal patch tests were prescribed, with the 'True test' basic set. Contact allergy was not confirmed. 'Prick-byprick' tests were prescribed concerning food often used in the household (carrot, celery, rye flour, wheat flour, cows' milk, hen egg, apple, tomato, banana, orange, cocoa, potato). Positive results of the prick-by-prick test were observed for potato (wheal/erythema $10 / 30 \mathrm{~mm} ;++++$ ), positive control - histamine $6 / 15 \mathrm{~mm}$, negative control - saline $0 / 0 \mathrm{~mm}$ [Fig. 2]. Based on the above results, contact eczema induced by potato protein was diagnosed. Allergen elimination and use of emolients were prescribed. A complete remission of skin lesions was obtained.

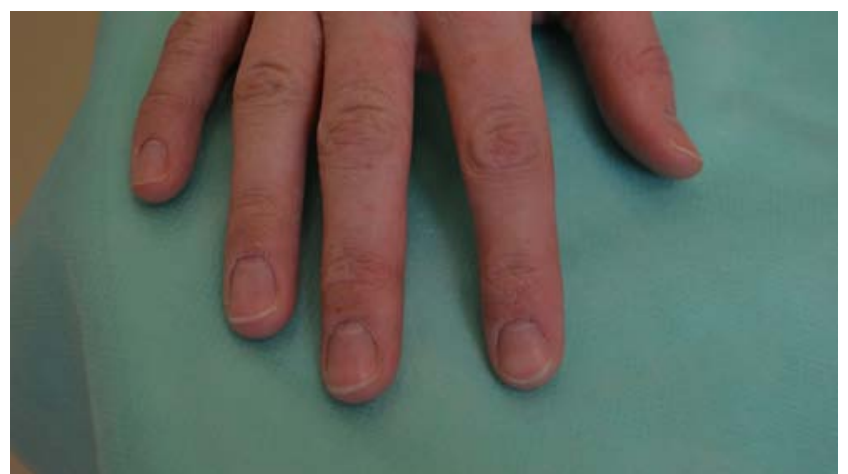

Figure 1. Erythemato-squamous skin lesions occurring on hands 


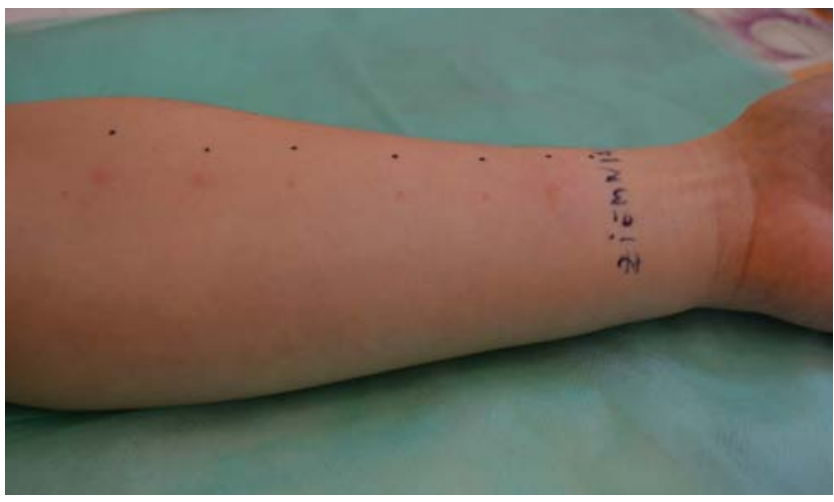

Figure 2. 'Prick-by-prick' tests

\section{DISCUSSION}

Protein contact dermatitis is a unit described for the first time in 1976 by Danish researchers as an allergic reaction caused by skin exposition to food [3]. A feature that differentiates this nosological unit from the classical contact allergy is a higher mass of the molecule inducing the reaction.

In 1983, Veien et al. defined the criteria for diagnosing PCD: chronic and recurrent dermatitis provoked by contact with proteinaceous material, acute urticaria or vesicular eruption occurring few minutes after contact with the product, patch tests usually negative, direct contact tests usually positive [4, 5]. All the above criteria were fulfilled in the described case.

PCD is rarely diagnosed, which is why there is no substantial epidemiologic data. It is estimated that about $50 \%$ of cases are related to atopy. It occurs more often in subjects with a damaged dermal-epidermal barrier, for example, in ICD, physical factors (burns), chemical factors (detergents), increased hydratation (washing hands often), prolonged occlusion (gloves). The damage probably facilitates the penetration of high-molecular-weight proteins into the skin [6]. Protein-induced contact eczema most often occurs in cooks, veterinarians and dairy workers [5]. On the other hand, the patient described in the presented case study is an office-worker, and did not belong to any of the abovementioned working groups.

The dermatological symptoms usually appear on the skin of hands, wrists and forearms, more rarely they concern only the finger tips. In exceptional cases, they can also appear on the face [7]. Apart from the lesions that are typical for eczema, urticaria or vesicular eruption occurring a few minutes after contact with the inducing factor, may appear on the skin. A relatively common symptom of the disease is chronic paronychia [8]. The skin lesions are accompanied by itching, burning, pricking and pain.

Most often, the same products eaten by subjects do not produce any effects. Rarely observed reactions are: generalised skin reaction, angioedema, gastrointestinal symptoms, allergic rhinitis, asthma, but they cannot be entirely excluded in the course of PCD; therefore, the patients should be informed about possible systemic symptoms after ingestion of the allergising protein [5]. The described patient, however, denied the above-reactions after eating potatos.

Products containing proteins that are most often responsible for the development of contact dermatitis are commonly divided into 4 groups (Tab. 1) [1].
Table 1. Products containing proteins that are most often responsible for the development of contact dermatitis divided into 4 groups [1]

\begin{tabular}{|c|c|c|}
\hline 1 & $\begin{array}{l}\text { Fruits } \\
\text { Vegetables } \\
\text { Spices } \\
\text { Plants }\end{array}$ & $\begin{array}{l}\text { almonds, banana, beans, cumin, carrots, castor oil, cauliflower, } \\
\text { celery, chickory, chrysanthemum, cardamine, dill, cucumbers, } \\
\text { curry, eggplant, endives, figs garlic, hazelnuts, peanuts, } \\
\text { horseradish, kiwi, lemons, mushrooms, onions, paprika, parsley, } \\
\text { parsnips, pineapples, tomatoes }\end{array}$ \\
\hline 2 & $\begin{array}{l}\text { Animal } \\
\text { proteins }\end{array}$ & $\begin{array}{l}\text { blood (pig, cow, sheep), mucus of amphibians, milk, dairy } \\
\text { products, cheese, egg yolk, fish (cod, cuttlefish, lobster, } \\
\text { flounder, clams, shrimp, mackerel), animal offal, meat (beef, } \\
\text { pork, poultry, horse meat, mutton), saliva of animals, wool, } \\
\text { animal skin, worms/larvae (e.g. annelid worms living in the } \\
\text { Baltic Sea, Nereisdiversicolor) }\end{array}$ \\
\hline 3 & Grain & rye flour, barley flour, wheat flour, oats \\
\hline 4 & Enzymes & a-amylase, celulase, glucoamylase, papain, protease \\
\hline
\end{tabular}

The PCD pathogenesis takes into account type I hypersensitivity reaction, mediated by allergen-specific IgE in a person sensitized earlier. Some authors claim the possibility of co-occurrence of reactions of types I and IV, due to the existing positive results of delayed patch tests, but this thesis is difficult to prove in most cases [1].

A golden standard in the PCD diagnostics are prick-tests: commercial or with fresh material [9]. If they are negative, it is acceptable to perform a test by rubbing the skin with the tested material, or with its application to the damaged epidermis [10]. Evaluation of the specific IgE level is possible if a known protein participates in inducing the reaction, but many alergising proteins remain unidentified [11].

Protein contact dermatitis is a dermatose that is not often diagnosed. However, it should be remembered that a wide spectrum of protein allergens with which the patients have wider and wider contact; for example, raw and smoked fish in popular Japanese cooking, numerous herbs proposed in alternative medicine and protein hydrolysates in new cosmetics. A detailed PCD diagnostics is very important for obtaining the optimal treatment results.

\section{REFERENCES}

1. Johansen JD, Frosch PJ, Lepoittevin JP (Eds.); Contact Dermatitis 5th ed. 2011 Springen-Verlag,Chapter 21: Goossens A, Amaro C; Protein Contact Dermatitis; pp 407-413

2. Gliński W, Kurek M. Alergia kontaktowa na pokarm. Alergia. 2002; 1 (12): 13-14. (in Polish)

3. Hjorth N, Roed-Petersen J. Occupational protein contact dermatitis in food handlers. Contact Dermatitis. 1976; 2(1): 28-42.

4. Veien NK, Hattel T, Justesen O, Nørholm A. Causes of eczema in the food industry. Derm Beruf Umwelt. 1983; 31(3): 84-6.

5. Levin C, Warshaw E. Protein contact dermatitis: allergens, pathogenesis, and management. Dermatitis. 2008; 19(5): 241-51.

6. Janssens V1, Morren M, Dooms-Goossens A, Degreef H. Protein contact dermatitis: myth or reality? Br J Dermatol. 1995; 132(1): 1-6.

7. Doutre MS. Occupational contact urticaria and protein contact dermatitis. Eur J Dermatol. 2005; 15(6): 419-24.

8. Tosti A1, Guerra L, Morelli R, Bardazzi F, Fanti PA. Role of foods in the pathogenesis of chronic paronychia. J Am Acad Dermatol. 1992; 27(5 Pt 1): 706-10.

9. Rocha J1, Pereira T, Sousa-Basto A, Brito C. Occupational protein contact dermatitis: two case reports. Case Rep Med. 2010; 2010: 489627.

10. Wüthrich B. Protein contact dermatitis. Br J Dermatol. 1996; 135(2): 332-3.

11. Barata AR1, Conde-Salazar L. Protein contact dermatitis-case report. An Bras Dermatol. 2013; 88(4): 611-3. 